\title{
Imagens contrastantes da morte nos Carmina de Horácio
}

\author{
Contrasting images of the death in Horace's Carmina
}

\section{RESUMO}

A morte é um tema central nos Carmina de Horácio. Esses cantos, ao lidarem com a transcendência, esconjuram a ameaça da morte. Imagens contrastantes da morte e do destino dos seres humanos surgem na lírica político-religiosa do poeta, partindo da dissolução do indivíduo na sombra e no pó à celebração post mortem daqueles que merecem ser cantados, como Cleópatra, o divino Augusto e o próprio Horácio.

Palavras-chave: Horácio - Cantos - post mortem - Imortalidade Divinização

\begin{abstract}
Death is a central theme in Horace's Carmina. These songs, dealing with transcendental issues, placate the threat of death. Contrasting images of the death and the fate of human beings arise in the vate's political-religious lyric. The poet moves between the individual's dissolution in the shadow and dust and the post mortem celebration of those who deserve to be sung, as Cleopatra, the divine Augustus, and Horace himself.
\end{abstract}

Keywords: Horace - Song - post mortem - Immortality - Divinisation

* Doutora em História pela Universidade Federal Fluminense (UFF), professora de História Antiga na UNIRIO. Atua no ensino e na pesquisa da vida intelectual e política na República romana tardia e, especialmente, no estudo sistemático da religião romana. É membra do Núcleo de Estudos e Referências da Antiguidade e do Medievo (NERO-UNIRIO), do Núcleo de Representações e Imagens da Antiguidade (NEREIDA-UFF) e da UMR 8210 (Unidade Mista de Pesquisa) em Anthropologie et Histoire des Mondes Antiques (Anhima - Paris). Visitor Fellow na School of History, Classics and Archaeology da Newcastle University, UK. CV: http://lattes.cnpa.br/4076444785733929 
Erigi monumento mais duradouro do que o bronze, e mais alto do que as decaídas, régias Pirâmides, quem nem a chuva voraz, nem o Aquilão, impotente, poderão destruir, nem dos anos a incontável sucessão e a passagem dos tempos.

Não morrerei de todo, e de mim a maior parte escapará a Libitina. No louvor dos pósteros crescerei renovado, enquanto ao Capitólio ascender

o Pontífice com a Vestal silenciosa.

De mim se dirá que, onde o Áufido corre impetuoso e onde Dauno, escasso em águas, sobre povos agrestes reinou, do nada me erguendo, fui o primeiro que à Itálica medida afeiçoou o carme eólico. Podes sentir orgulho pelo mérito alcançado. E tu, ó Melpómene, digna-te com o louro de Delfos cingir-me a fronte. ${ }^{1}$

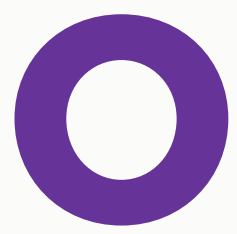

carmen romano estava intrinsecamente ligado à religião e aos rituais. $^{2}$ Nos Carmina ${ }^{3}$ de Horácio vemos verdadeiras invocações líricas e referências religiosas ocorrem em muitas passagens, mas, excetuando-se o Carmen Saeculare, não há registro de outras comissões horacianas para rituais públicos (Griffin, 2007, p. 182). Os Carmina, portanto, parecem não ter sido escritos para rituais pro populo, o que não diminui seu interesse para os estudos da religião romana. Textos como esses eram parte integrante da cultura religiosa romana e radicavam na sociedade em que foram criados, participando do discurso religioso contemporâneo. ${ }^{4} \mathrm{O}$ termo carmen significa aquilo que entendemos por "canto", e há que abstrair da ideia moderna de poesia para compreender o seu sentido, pois um carmen era composto pelo poeta a partir de certas estruturas métricas, visando a uma execução oral, um canto ou uma recitação com acompanhamento musical, geralmente um instrumento de corda. Os quatro livros contêm 103 carmina, e seus temas são os mais diversos: a celebração da vida, questões políticas, a morte, a esperança da imortalidade e o elogio da poesia e do poeta como seus promotores.

Um de seus temas foi particularmente bem sucedido na tradição ocidental, o carpe diem, em que o poeta aconselha seus ouvintes e leitores a colher o dia, este dia. Este tema,

1 Exegi monumentum aere perennius regalique situ pyramidum altius, quod non imber edax, non aquilo impotens possit diruere aut innumerabilis annorum series et fuga temporum. non omnis moriar multaque pars mei vitabit Libitinam; usque ego postera crescam laude recens, dum Capitolium scandet cum tacita virgine pontifex. dicar, qua violens obstrepit Aufidus et qua pauper aquae Daunus agrestium regnavit populorum, ex humili potens, princeps Aeolium carmen ad Italos deduxisse modos. sume superbiam quaesitam meritis et mihi Delphica lauro cinge volens, Melpomene, comam. Tradução de Pereira (1986).

2 Sobre este ponto ver Habinek (2005), que coerentemente critica o uso do termo "literatura" para designar os carmina romanos, inserindo-os no âmbito do poder ritualizado. Ver também Feeney (2004), sobre as interações entre a poesia romana e os rituais religiosos.

3 Não há notícias da data precisa em que Horácio iniciou sua composição, mas é provável que coincida com sua transferência para a villa sabina que lhe foi dada por Mecenas e seu afastamento relativo da urbs (Putnam, 1986, p. 25-6). Os destinatários são pessoas de várias tendências e tipos: amigos pessoais, ligações políticas, mulheres e homens com os quais Horácio teve ou desejou ter relações amorosas, escritores etc. Dentre os destinatários, destacam-se Augusto e Mecenas, nomes significativos para a carreira literária e o reconhecimento público do poeta. (Barchiesi, 2007).

4 Edição em latim utilizada: SHOREY, Paul \& LAING, Gordon J. Horace, Odes and Epodes. Chicago: Benj. H. Sanborn \& Co., 1919. As traduções do latim são da autora, exceto quando explicitado. 
devido a uma longa história de más interpretações, costuma ser hoje entendido como "desfrute a vida", no sentido de um imperativo sensualista neste mundo que rende culto ao ideal da eterna juventude e o identifica com a frivolidade e o consumismo. Longe disso, em seus Carmina o poeta canta uma constante presença da morte, mesmo nos momentos mais aprazíveis da vida. Não é infundado dizer, portanto, que a morte é um elemento central dos cantos.

Nos Carmina, imagens da morte e do post mortem são recorrentes. Por um lado, a ênfase no caráter mortal do ser humano, a irrevogabilidade de sua vida frente à constante renovação que significam os ciclos naturais. A própria sucessão das estações e a mudança natural advertem sobre a mortalidade humana e a dissolução do indivíduo, ou sua transformação em triste sombra sem memória, em uma desconhecida e longa noite. Por outro lado, surgem nos cantos indivíduos excepcionais que, pela coragem ou pela ação virtuosa, venceram a dissolução da morte e atingiram a imortalidade ou mesmo a divinização; pessoas que contaram com o vate, o poeta-cantor dos deuses, que os celebrou e imortalizou nos versos e, ao fazê-lo, divinizou a si próprio. Minha proposta é apresentar uma breve leitura das imagens contrastantes da morte dos Carmina, destacando algumas passagens que considero significativas, para uma compreensão do percurso horaciano da dissolução do ser humano pela morte, à imortalidade garantida pelo e para o sagrado vate.

\section{"Somos pó e sombra": a morte incontornável}

De formação filosófica epicurista, Horácio provavelmente conhecia a doutrina segundo a qual a morte significava apenas a dispersão dos átomos. Por isso, qualquer consideração sobre a morte era, de fato, um ponto de vista formulado e baseado no âmbito da vida, seguindo-se que não era possível conhecer a morte e que, portanto, seria inútil ocupar-se dela. Contudo, Horácio era um poeta, e não um filósofo buscando qualquer precisão conceitual, e não demonstra compartilhar tais ideias. Em seus Carmina, aceitando a doutrina epicurista para a vida, o poeta expressa uma constante preocupação com a morte, que surge como uma ameaça aos momentos mais aprazíveis da vida, impedindo uma vida realmente segura e cômoda, despreocupada do futuro. Mais ainda, a imagem de um tipo de vida após a morte surge em muitas passagens de seus carmina, uma espécie de vagar nas sombras.

O carmen 1.4 é aberto com a chegada da primavera e a declaração de que a morte iguala todas as pessoas:

A pálida morte golpeia do mesmo modo as cabanas dos pobres e as fortalezas dos reis. Ó, afortunado Sestio, a suma de uma vida breve nos impede de manter uma longa esperança. Já te oprimiram a noite e os lendários Manes e a ruinosa morada de Plutão. ${ }^{5}$

5 Shorey \& Laing, 1919: Carm., 1.4.13-17: pallida Mors aequo pulsat pede pauperum tabernas regumque turris. o beate Sesti, vitae summa brevis spem nos vetat inchoare longam; iam te premet nox fabulaeque Manes et domus exilis Plutonia... 
Se os mais poderosos e os mais humildes não escapam à morte, no carmen 2.3 o poeta declara que a morte é o único acontecimento realmente previsível na vida e prega a insignificância das riquezas, já que será imperativo abandoná-las: "Todos somos destinados ao mesmo lugar: se agita a sorte de todos, que mais cedo ou mais tarde sairá da urna e nos colocará na barca em direção a um exílio eterno". ${ }^{6}$ Este carmen é inciado com um chamado ao destinatário, Délio, para que recorde-se de que está sujeito à morte, e que deve manterse íntegro nas circunstâncias favoráveis ou desfavoráveis da vida. De um lado, o poeta canta aquilo que é mutável, diante do que o sábio deve manter-se imperturbável; de outro, a morte surge como o primeiro objeto da ataraxia, e só a partir da sua aceitação como um dado natural que se pode ter uma vida feliz. ${ }^{7}$

Em um dos mais celebrados de seus poemas em nossos dias, o poeta se dirige a uma mulher, Leuconoe, que pretende conhecer seu futuro a partir da astrologia (os "números babilônicos"). O poeta lhe diz que não tente averiguar o quanto lhe resta de vida, mas que aceite, com atitude sábia, aquilo que lhe trará o futuro:

Não procures, Leuconoe, - impio será sabê-lo - que fim a nós dois os deuses destinaram; não consultes sequer os números babilónicos: Melhor é aceitar! E venha o que vier! Quer Júpiter te dê ainda muitos invernos, quer seja o derradeiro este que ora desfaz nos rochedos hostis ondas do mar Tirreno, vive com sensatez destilando o teu vinho e, como a vida é breve, encurta a longa esperança. De inveja o tempo voa enquanto nós falamos: trata pois de colher o dia, o dia de hoje, que nunca o de amanhã merece confiança. ${ }^{8}$

As palavras "encurta a longa esperança" dirigidas a Leuconoe, referidas ao lapso da vida, têm um sentido negativo. O último verso expressa a ideia de que não há que confiar no futuro, pois este projeta no hinc et nunc a sombra da morte. A condição para bem viver o momento presente (carpe diem) é não criar grandes expectativas para o futuro. Uma imagem do canto contribui para essa interpretação: o mar se desgasta ao se chocar incessantemente contra os rochedos, enquanto o poeta aconselha Leuconoe, expressando a impossibilidade de dominar o futuro. O inverno, ou seja, o próprio tempo representado por uma das estações do ano, desgasta o mar, o que significa que é inútil resistir ao decurso do tempo. Assim, a felicidade é obtida refugiando-se no breve espaço do momento presente, tornando-o proveitoso (Curtius,

6 Idem, Carm., 2.3.25-28: omnes eodem cogimur, omnium versatur urna serius ocius sors exitura et nos in aeternum exilium inpositura cumbae.

7 Esta ideia está de acordo com as Cartas a Meneceo 124, em que Epicuro diz ser necessário pensar que a morte nada tem a ver com o ser humano, já que é ausência de sensação, e o bem e o mal existem justamente a partir da sensação. Sobre os Carmina, ver Beltrão (2008).

8 Shorey \& Laing, 1919: Carm., 1.11: Tu ne quaesieris, scire nefas, quem mihi, quem tibi finem di dederint, Leuconoe, nec Babylonios temptaris numeros. ut melius, quidquid erit, pati. seu pluris hiemes seu tribuit luppiter ultimam, quae nunc oppositis debilitat pumicibus mare Tyrrhenum: sapias, vina liques et spatio brevi spem longam reseces. dum loquimur, fugerit invida aetas: carpe diem quam minimum credula postero. Tradução de Mourão-Ferreira (2003). 
1979, p. 133). Nesse sentido, o tempus fugit é qualificado como algo odiado e temido. ${ }^{9}$

No carmen 2.14, o poeta caracteriza Plutão, o deus do submundo. Não é possível aplacar este deus sacrificando touros em sua honra, a fim de que adie a chegada da velhice e da morte. $\mathrm{O}$ afastamento da doutrina epicurista sobre a morte como o simples fato da dispersão dos átomos surge nos versos como a aceitação de uma imagem homérica (cf. Od. 9), a de Odisseu vendo Aquiles como uma sombra a mais dentre as sombras de outros mortos. Essa sombra, destino de todos os mortais, é algo distinto do nada que proclamava o epicurismo helenístico. O ser humano ao morrer não se desintegra, então, em átomos que compõem a matéria da qual está formado, mas se dirige a um além, um transmundo, e ali permanece como uma sombra sem memória.

Em outros cantos o post mortem tem uma dimensão maior, criando uma imagem na qual elementos míticos e religiosos são mais ressaltados. Por exemplo, no carmen 1.24, vemos Mercúrio conduzindo a turba dos mortos e, em 2.13, há uma vívida imagem do Hades. Trata-se de uma mescla entre mito grego e religião funerária romana, na qual ao morrer, o indivíduo passa a um estado impessoal, o estado de "antepassado" na coletividade infernal dos Manes (Bustamante, 2014). E, em 3.1.14-16, lemos "Com igual lei a necessidade sorteia aos afortunados e aos infelizes; sua espaçosa urna agita todos os nomes". ${ }^{10} \mathrm{O}$ desejo de riqueza e a sede de glória e de honra estão ligados ao temor da morte, como em Lucrécio (Beltrão, 2007) e a necessitas é identificada com a morte. Há, então, uma necessidade incontornável no suceder das coisas, e o que resta aos mortais é uma atitude de resignação.

No carmen 4.7 essa visão é clara, especialmente em seu epílogo pessimista em relação à fragilidade de vida e ao caráter mortal do ser humano frente às constantes renovações dos ciclos naturais. A sucessão das estações e a mudança cotidiana advertem sobre a mortalidade humana, mesmo que na natureza a morte seja apenas um estado transitório. O tema da transformação cíclica se concretiza na referência à deusa Luna, sempre mutável, e a menção a Diana e Hipólito, em que o segundo é condenado à perda de sua identidade entre as sombras. A seu destinatário, Torquato, o poeta canta que ao morrer, todos irão para onde está o "pai Eneias", Túlio e Anco, e que se tornarão pó e sombra (pulvis et umbra sumus). A ideia comum aqui é que mesmo o mais poderoso perde inevitavelmente seu poder. Nem sequer o amor pode amenizar o rigor da morte. Ao morrer, perde-se a memória, ao beber "as águas de Lethe".11

9 Sobre o tema do carpe diem, ver Beltrão (2008 e 2009). Carpe diem não se refere, rigorosamente falando, a buscar a diversão constante e frívola, mas a evitar o sofrimento, na disciplina epicurista. No carmen 2.3, por exemplo, torna-se claro que o tipo de vida despreocupado e fácil é uma atitude negativa, que não leva à felicidade. Nele, Horácio aconselha a Délio, seu destinatário, que se mantenha imperturbável perante as circunstâncias mutáveis da vida, o que corresponde ao ideal epicurista, e finalmente, como permitem as Parcas, que ordene aos seus escravos que tragam o necessário para o banquete (o vinho, os azeites, as rosas etc.). Esse carmen começa com uma advertência a Délio: que se recorde sempre, nas ocasiões favoráveis e nas desfavoráveis, de que deve manter sua mente equilibrada e só assim conseguirá a paz necessária para viver sua efêmera existência de acordo com os ditames da virtus.

10 Shorey \& Laing, 1919: Carm., 3.1.14-16: aequa lege Necessitas sortitur insignis et imos, omne capax movet urna nomen.

11 Idem, Carm., 4.7.27-28. 


\section{A deliberata morte de Cleópatra}

Uma morte, contudo, é especialmente celebrada nos Carmina, a morte do fatale monstrum, Cleópatra, capaz de trazer a destruição não apenas a indivíduos, mas a toda a coletividade romana. O perigo da dissolução não é só um risco individual, mas também os povos e os poderes sucumbem a ela. Neste ponto, passamos de uma "lírica individual" à "lírica cívica", seguindo a renomada distinção de Ernst Curtius (1979). Em linhas gerais, o conjunto dos Carmina tem como pano de fundo o tema das causas das guerras civis, que para o poeta representavam uma ameaça para a ordem romana, e a reforma moral - ética e religiosa - que permitiria a Roma escapar à destruição coletiva (cf. Beltrão, 2008).

No Carmen 1.37 os versos nunc est bibendum propõem a celebração da derrota de Cleópatra, notícia que chegou a Roma no outono de 30 AEC. Cleópatra surge nesses versos como a encarnação do perigo, já debelado, que ameaçava Roma. O poeta escreve que ela se atrevera a ameaçar Roma, por estar ébria da doce Fortuna ${ }^{12}$, força em nítida oposição à virtus. O poeta canta a batalha do Actium e o suicídio de Cleópatra em Alexandria, eventos separados por um ano, que são apresentados em uma mesma sequência narrativa. ${ }^{13}$ Trata-se de uma estrutura narrativa na qual o poeta esquematiza e estiliza eventos, criando uma espécie de aition para o governo de Augusto. A batalha do Actium e a morte de Cleópatra surgem como o clímax da narrativa do fim de uma sequência de guerras civis mortais e o começo de uma "nova era":

Agora é beber, agora, os pés livres, é a terra pulsar, agora era tempo de ornar os coxins dos deuses com os festins sálios, camaradas. Até hoje era ímpio tirar o Cécubo da adega ancestral, enquanto a rainha tramava insanas ruínas ao Capitólio e a morte ao império com um bando de homens torpes por vício corrompido, orgulhosa a esperar seja o que fosse e ébria da doce fortuna. Mas abrandou sua fúria só um navio a custo salvo das chamas, César reduziu sua mente em delírios mareóticos a temores reais e, desde a Itália correndo, perseguindo-a a remos, tal qual falcão as frágeis pombas ou ágil caçador a lebre nos campos gélidos da Hemônia, para pôr em correntes o monstro fatal. Ela, a morte mais nobre almejando, não temeu a espada como as mulheres, nem com frota veloz buscou praia oculta, ousou contemplar, com rosto sereno, seu palácio extinto e, audaz, tocar ásperas serpentes para que o negro veneno se entranhasse em seu corpo, mais feroz na morte deliberada: nega que a conduzam cruéis liburnas, como simplória, em soberbo

12 Idem, Carm., 37.11-12.

13 A batalha do Actium ocorreu em setembro de 31, enquanto a conquista de Alexandria e o suicídio de Cleópatra ocorreram em agosto de 30 AEC. A mesma amálgama de eventos pode ser vista, e.g., na Aeneida, 8.714-728, em que Virgílio os une ao triplo triunfo de Otaviano em 29 e à dedicação do templo de Apolo no Palatino, em 28 AEC. Edição utilizada: Vergil. Bucolics, Aeneid, and Georgics of Vergil. J. B. Greenough (ed.). Boston Ginn \& Co. 1900. 
triunfo, mulher em nada humilde. ${ }^{14}$

Uma ausência à primeira vista notável no poema é Marco Antônio, mas havia razões políticas para isso. A guerra fora apresentada pelo jovem César como uma guerra estrangeira contra uma rainha estrangeira, chegando ao ponto de apelar ao colégio dos fetiales, sacerdotes especialistas na declaração e condução da guerra contra inimigos externos. ${ }^{15}$ Desse modo, a exclusão do romano Marco Antônio e a ênfase na rainha egípcia é compreensível. Ainda que Antônio tivesse comandado as forças partidárias de Cleópatra, Horácio apresenta Cleópatra como a única liderança e o grande perigo (Lowrie, 1997, p. 137-164). ${ }^{16}$ Certamente havia também razões políticas e dinásticas para tal: no fim dos anos 20 AEC, quando o carmen é publicado, filhos e filhas de Antônio integravam a política dinástica da domus Augusta. Iulo Antônio, filho de Antônio com Fúlvia, era o candidato mais cotado para ser pretor e casar-se com Claudia Marcela, filha de Otávia. Cleópatra Selene, sua filha com Cleópatra, casara-se com o rei cliente Juba II da Mauritânia, enquanto Antônia Maior, filha de Antônio com Otávia e futura avó de Nero, casara-se com L. Domício Aenobarbo, e sua irmã Antônia Minor casaria com o filho de Lívia, Drusus, com quem teria Germânico e o imperador Claudio. Em suma, é compreensível eximir o pai desta ilustre prole de um papel destacado na oposição a Augusto (Williams, 1974, p. 147-155; Roller, 2004, p. 203). Horácio também não menciona o grande número de romanos lutando com Antônio, outra ausência justificável, dada a ênfase no caráter estrangeiro das forças inimigas, minimizando a imagem de uma guerra civil. Os inimigos mencionados além de Cleópatra são os eunucos "deformados e efeminados" da corte da rainha. ${ }^{17}$

Há claros elementos de gênero e de poder aqui. O falcão é gramaticalmente masculino, agressivo e vitorioso, representando o jovem César, enquanto as pombas e as ovelhas estão no polo feminino, fracas e conquistadas, representando Cleópatra e seus seguidores. Trata-se de um desequilíbrio de poder entre predador e presa, e está claramente implicado que um necessariamente dominaria o outro. Mas, na narrativa da morte de Cleópatra, uma significativa mudança ocorre. A figura de Cleópatra se transforma rapidamente (Feldherr, 2010). De um fatale monstrum $^{18}$ passa a ser uma exótica, porém digna, rainha ${ }^{19}$. Cleópatra é digna não somente

14 Shorey \& Laing, 1919: Carm., 1.37: Nunc est bibendum, nunc pede libero / pulsanda tellus; nunc Saliaribus / ornare pulvinar deorum tempus erat dapibus, sodales. / antehac nefas depromere Caecubum / cellis avitis, dum Capitolio / regina dementis ruinas, / funus et imperio parabat/ contaminato cum grege turpium /morbo virorum quidlibet inpotens sperare fortunaque dulci/ebria. sed minuit furorem / vix una sospes navis ab ignibus / mentemque lymphatam Mareotico / redegit in veros timores / Caesar ab Italia volantem / remis adurgens, accipiter velutmollis columbas aut leporem citus / venator in campis nivalis / Haemoniae, daret ut catenis / fatale monstrum. quae generosius / perire quaerens nec muliebriter / expavit ensem nec latentis / classe cita reparavit oras. / ausa et iacentem visere regiam / voltu sereno, fortis et asperas / tractare serpentes, ut atrum / corpore conbiberet / venenum, / deliberata morte ferocior; / saevis Liburnis scilicet invidens/ privata deduci superbo, / non humilis mulier, triumpho. Tradução de Moreira (2015).

15 Sobre os sacerdotes fetiales ver: Beltrão (2012) e Santangelo (2008).

16 Virgílio, Aen., 8.685-688, por sua vez, apresenta Antônio como o comandante supremo, e Cleópatra é apenas sua Aegyptia coniunx, apoiando o verdadeiro líder com forças orientais.

17 Shorey \& Laing, 1919: Carm., 1.37.9-10. Outro grande ausente do poema é Agripa, cujo papel no Actium foi ressaltado por Virgílio, Aen., 8. 682-684); Plutarco, Ant., 65.1 e Dio Cassio, 50.13.5. Talvez a ausência de Agripa se deva ao esquematismo extremo do poema, criando a polarização excludente entre Otávio e Cleópatra. As edições aqui utilizadas foram: De Plutarco: Plutarch. Plutarch's Lives. Bernadotte Perrin (ed.). Cambridge, MA. Harvard University Press. London:. William Heinemann Ltd. 1920. 9. e De Dio Cassio: Cassius Dio Cocceianus. Dio's Roman History. Earnest Cary \& Herbert Baldwin Foster (ed.). London: William Heinemann, 1914.

18 Shorey \& Laing, 1919: Carm., 1.37.21.

19 Idem, Carm., 1.37.22-32. 
por evitar a humilhação de ser exibida em um triunfo e ser executada, mas também por sua linhagem. $O$ termo generosius ${ }^{20}$ refere-se à linhagem (genus), e Cleópatra é apresentada como alguém que quer morrer de um modo digno de seus ancestrais, como a última representante dos grandes Ptolomeus do Egito.

A figura de Cleópatra revela a flexibilidade do gênero. Retratada na primeira parte do canto como uma mulher irracional e fraca, Cleópatra, em 1.37.22-23, abandona a "debilidade feminina" ao não temer a espada. A espada, obviamente, significa a morte, mas também alude à hierarquia dos modos tradicionais de suicídio na tragédia ática, na qual a espada é geralmente reservada às personagens masculinas e só raramente utilizada por personagens femininas (Loraux, 1988; Lowrie, 1997). Apesar de Cleópatra ao fim e ao cabo utilizar um modo de suicídio especialmente "exótico", o futuro que ela prepara para si é tradicionalmente masculino. Há aqui um forte contraste entre a fraqueza "feminina" de Cleópatra, a perdedora do Actium, e a "masculina" afirmação de seu status e dignidade em um nobre suicídio.

O suicídio de Cleópatra é narrado por Horácio de um modo que ressalta a plasticidade do gênero e, ao mesmo tempo, requisita elementos do suicídio masculino, mantendo elementos exóticos, como o auto-envenenamento pela mordida da serpente. A metáfora do beber o veneno (combibiret) inverte a imagem simposiasta da primeira metade do poema (Lowrie, 1997, p. 162), e a rainha é representada de modo resoluto diante do desastre, corajosamente lamentando mais a destruição de seu palácio do que sua própria morte. Cleópatra se suicida com a apropriada serenidade, o que é reforçado pela expressão deliberata morte ${ }^{21}$, que sugere um cuidadoso planejamento da cena da morte. Do mesmo modo, é indicado que Cleópatra tinha determinação e astúcia para matar-se e frustrar os planos do jovem César, que seguramente exibiria a rainha em seu triunfo em Roma. ${ }^{22}$

Cleópatra é uma figura central na vida política romana e no Carm 1.37 é a personagem principal, mais importante que Augusto. O canto começa, então, com uma imagem positiva da bebida celebratória (nunc est bibendum...), passando a uma imagem negativa da rainha "ébria da doce fortuna" (fortunaque dulci ebria) e impotente (inpotens) em seus planos para destruir o Capitólio. Sua entourage é formada por homens vergonhosos (contaminatio cum grege turpium morbo virorum), uma referência aos eunucos de sua corte em Alexandria. O propósito do César é pôr este fatalem monstrum em correntes. Na segunda parte, contudo, por não temer a morte, Cleópatra é nec muliebriter, não é feminina, mas a referência final à rainha é que ela é uma mulher não humilde. Sua morte envolvia uma decisão racional, quando tudo estava perdido, e um último gesto de desafio ao vencedor. Se o papel de Antônio é eliminado no poema, obscurecendo os traços da guerra civil, a figura de Cleópatra, após a execração inicial, é transformada em uma figura digna de ser cantada pelo poeta, e dignificante no clímax que leva o jovem César Otaviano ao poder e à "salvação" de Roma. Longe de um desapontamento pelo suicídio, a perspectiva política do canto requeria que a liderança da oposição ao futuro

20 Idem, Carm., 1.37.21.

21 Idem, Carm., 1.37.30

22 Cf. Plut. Ant. 78.3; Suet. Aug. 17.4; D.C. 51.11.3. As versões de Plutarco e Dio Cassio se encontram na nota 17 acima e a tradução de Suetonio utilizada foi a seguinte: Suetonius. The Life of the Twelve Caesars. J. C. Rolfe (ed.). Cambridge-MA: Harvard University Press, 1914. 
Augusto fosse uma figura nobre, cuja derrota e morte eram também gloriosas.

\section{“Tua idade, César...": Augusto e a imortalidade da virtus}

A questão da felicidade era uma preocupação central para o poeta, que a vinculava à restauração da antiga virtus, então abalada por Fortuna. O primeiro vocábulo, derivado de vir (homem), marca simultaneamente uma atividade e uma qualidade, adquirindo o sentido geral de mérito que designa a coragem guerreira, assim como é justaposto na língua do direito público, designando o que é próprio aos viri (homens) (Ernout e Meillet, 2001, p. 738-9, s.v. uir). Mas não era suficiente a reforma moral de toda a sociedade. Era também necessária a presença de um indivíduo que atuasse como mediador entre as esferas divina e humana. A figura de Augusto, destacada como o reorganizador do mundo romano, assume este papel nos Carmina. O princeps surge com uma dupla natureza, humana e divina, e como tal tem um destino singular:

Tua idade, César, devolveu as fecundas messes aos campos e restituiu a nosso Júpiter as insignias arrebatadas às soberbas portas dos Partos, e fechou o templo de Jano Quirino, livre de guerras, impondo um freio à licenciosidade que escapava à reta ordem, e afastou as culpas, e recobrou as antigas artes, pelas quais se fortaleceram o nome latino e as forças ítalas, e a fama e a majestade do império se estenderam desde o nascimento do sol até seu hespério leito. ${ }^{23}$

No carmen 3.2, nem todos os seres humanos são iguais após a morte, mas os destinos últimos dependem das diferentes maneiras de viver. Só o vir que vive guiado pela virtus obterá a imortalidade. A virtus "abre o céu aos que não merecem morrer" ${ }^{24}$. E, em 3.30, o vir vence a mão do próprio Júpiter, que controla a vida e a morte:

Nem o impeto dos cidadãos que ordenam perversidades, nem o ameaçador rosto de um tirano, nem o Austro, turbulento rei do inquieto Adriático, nem a mão do fulminante Júpiter, comovem o firme espírito do homem justo e tenaz em seu propósito; se o mundo se desmoronara, destruído, suas ruínas o tocarão impretérito. ${ }^{25}$

Se no carmen 1.11, a imagem do mar que se debilita chocando contra os rochedos

23 Shorey \& Laing, 1919: Carm., 4.15.4-16: tua, Caesar, aetas fruges et agris rettulit uberes et signa nostro restituit lovi derepta Parthorum superbis postibus et vacuum duellis lanum Quirini clausit et ordinem rectum evaganti frena licentiae iniecit emovitque culpas et veteres revocavit artis, per quas Latinum nomen et Italae crevere vires famaque et imperi porrecta maiestas ad ortus solis ab Hesperio cubili.

24 Idem, Carm., 3.2.21-22.

25 Idem, Carm., 3. 3. 1-8): ustum et tenacem propositi virum non civium ardor prava iubentium, non voltus instantis tyranni mente quatit solida neque Auster, dux inquieti turbidus Hadriae, nec fulminantis magna manus lovis: si fractus inlabatur orbis, inpavidum ferient ruinae. Tradução de Mourão-Ferreira (2003). 
representa os esforços humanos impotentes contra os ditames de Júpiter, em 3.3, o César virtuoso assoma firme e indestrutível, vencendo as forças da natureza, como o vento, o terremoto e a morte. Escapar do ciclo de vida, morte e dissolução é reservado a indivíduos excepcionais, como Augusto, Hércules, Pólux, Baco, Rômulo. No carmen vemos, portanto, Augusto entre os deuses. A divinização é o prêmio pelo mérito de uma vida pautada pela justiça e pela constância, pelas quais se pode vencer a morte e alcançar as "alturas ígneas". Augusto, que encerrou as guerras civis, é equiparado a Rômulo, que pôs fim à maldição de Troia com a fundação de Roma. Augusto é o auctor, o segundo fundador e salvador.

Em 4.5, a divinização de Augusto se dá em vida pela adoração de seu numen, pelo qual os romanos vivem uma vida feliz. Mais ainda, para o comum dos mortais, o ciclo vida-morte pode ser detido com a transcendência. O mais significativo aqui é que a inicial concepção pessimista em relação à morte se transforma paulatinamente nos carmina. A virtus torna possível a imortalidade, e as imagens que o poeta requisita permitem depreender a busca de uma salvação da morte que tem lugar também em uma esfera comunitária, a partir da eternidade de Roma. Ao encerrar as causas das guerras civis - que, para o poeta, são causas de ordem moral que se apresentam como uma constante ameaça ao mundo romano -, Augusto assegurou a imortalidade coletiva de Roma.

Aquele que se sente ameaçado pela morte é como o mar que se fadiga em vão, descarregando seu ímpeto sobre as rochas da praia. Nas imagens contrastantes de Cleópatra e de Augusto, um mesmo fim é entrevisto: ser livre da opressão das circunstâncias e ter o domínio de si mesmo.

\begin{abstract}
O César, celebrado há pouco como outro Hércules por haver buscado o laurel que se paga com a morte, regressa vencedor, desde as costas hispânicas, a seu lar. Que sua mulher, que goza de um incomparável marido, se apresente, havendo sacrificado aos justos deuses, e a irmã do ilustre chefe, e as mães das virgens e dos jovens recémsalvos, adornadas com coroas de suplicante. Deixem vocês, rapazes e moças que já provaram varão, as palavras de mau augúrio. Este dia, verdadeiramente feliz para mim, deixará as funestas preocupações. Enquanto o César dominar a terra, não temerei nem o tumulto da guerra, nem morrer violentamente. Busca perfume, menino, e coroas, e um vinho que recorde a guerra marsa, se é que alguma ânfora pôde escapar das andanças de Espártaco. ${ }^{26}$
\end{abstract}

O carmen 3 começa cantando a impassibilidade do ser virtuoso diante das circunstâncias adversas, e há uma clara identificação de Júpiter com a Fortuna, imagens do mutável, da desordem dos cidadãos e do vento impetuoso. Júpiter e Fortuna são as forças que regem a

26 Idem, Carm., 3. 14: Herculis ritu modo dictus, o plebs, morte venalem petiisse laurum Caesar Hispana repetit penatis victor ab ora. unico gaudens mulier marito prodeat iustis operata sacris et soror clari ducis et decorae supplice vita virginum matres iuvenumque nuper sospitum; vos, o pueri et puellae iam virum expertae, male nominatis parcite verbis. hic dies vere mihi festus atras exiget curas ego nec tumultum nec mori per vim metuam tenente Caesare terras. i pete unguentum, puer, et coronas et cadum Marsi memorem duelli, Spartacum siqua potuit vagantem fallere testa... 
ordem natural, de modo que resistir ao seu poder revela o desejo de subtrair-se à ordem da natureza, que também afeta os povos e os estados. Em Roma, contudo, o temor da destruição desapareceu com a pax aeterna da era de Augusto, e a crença de que uma idade do ouro se realizara.

\section{À guisa de conclusão: a celebração da imortalidade poética}

Se no carmen 4.7 a imagem da morte a que todos os seres estão sujeitos é sintetizada na sentença "somos pó e sombra", no poema seguinte, 4.8, Horácio canta outro caminho post mortem. A ideia de que a canção confere a imortalidade tem, para nós, seu início em Homero, e aparece na poesia arcaica de Safo chegando a Píndaro e Teócrito, sendo familiar a Horácio e seus leitores através também de Baquílides, Simônides e Cícero. E o poeta declara: "A Musa não permitirá que morra o homem digno de louvor". ${ }^{27}$ Não a triste sombra do canto anterior, mas a Musa concede a imortalidade e a elevação àquele que merece ser cantado. Nos banquetes de Júpiter participam os seres de dupla natureza e grande valor: Castor e Pólux, Hércules e Baco, Rômulo e Augusto. A imortalidade da canção e de quem a profere é o tema principal do carmen 4.9, no qual é defendido que não só a épica, mas também a lírica imortaliza aqueles que cantam e os que são cantados. E os outros, os "não pranteados" pelo sagrado vate, destinamse ao esquecimento, em uma "desconhecida e longa noite". 28

O carmen 3.30 traz a imagem do ser que não é afetado pela morte, e o canto surge como o monumento indestrutível e imutável ante o tempo:

Erigi monumento mais duradouro do que o bronze, e mais alto do que as decaídas, régias Pirâmides, quem nem a chuva voraz, nem o Aquilão, 29 impotente, poderão destruir, nem dos anos a incontável sucessão e a passagem dos tempos. Não morrerei de todo, e de mim a maior parte escapará a Libitina. ${ }^{30}$

Libitina, a deusa que preside aos funerais, representa a morte (Scheid, 2004). O carmen salvará o poeta da morte. Este canto novamente dialoga com as imagens do Carm. 1.11, do mar que se desgasta chocando em vão contra os rochedos e da necessidade incontornável do passar do tempo. Em 3.30, ao contrário, os elementos da mudança - a chuva, o vento, o transcurso do tempo - de nada são capazes contra este monumento mais duradouro que o bronze. E o poeta já exigira: “Estejam ausentes do meu funeral as fúteis nênias fúnebres, gritos

27 Idem, Carm., 4.8.28-29: dignum laude virum Musa vetat mori,caelo Musa beat.

28 Idem, Carm., 4.9: sed omnes inlacrimabiles urgentur ignotique longa nocte, carent quia vate sacro.

29 Aquilo, o vento norte.

30 Shorey \& Laing, 1919: Carm., 3.30.1-7: Exegi monumentum aere perennius regalique situ pyramidum altius, quod non imber edax, non aquilo impotens diruere aut innumerabilis annorum series et fuga temporum. non omnis moriar multaque pars mei vitabit Libitinam. Tradução de Pereira (1986). 
e lutos desagradáveis, contenham o clamor e rejeitem as honras vãs do sepulcro". ${ }^{31}$

As neniae eram cantadas pelas praeficae em honra dos mortos nos funerais (Fest. Naenia. 155-27L; North, 2015; Horster, 2007; Richlin, 2001). Neste canto profético sobre sua própria imortalidade poética, Horácio ordena que não haja nênias nem lamentos funerários por serem supérfluos em seu túmulo. As nênias compunham os últimos estágios de um funeral romano e, para Thomas Habinek (2005, p. 245), essa passagem confirma que o canto das praeficae nos ritos fúnebres mantinha o morto sob controle, destinando-o à coletividade infernal dos Manes, mas o poeta declara que, transformado em cisne, será levado às alturas. ${ }^{32} \mathrm{Na}$ religio funebris, a individualidade dos seres humanos após a morte submergia na comunidade dos Manes. De certo modo, os mortos sobreviviam e eram ainda capazes de causar danos aos vivos, caso não tratados apropriadamente pelos descendentes (Bustamante, 2014; Beltrão, 2016). Assim, as nênias eram, de fato, o fim para o ser humano individual, mas Horácio, mediador entre os deuses e os humanos, é afim com o divino, escapando à dissolução da morte: "E tu, ó Melpómene, digna-te com o louro de Delfos cingir-me a fronte". 33

Horácio, portanto, não era um epicurista ortodoxo, para quem morrer é a simples desintegração dos átomos, e apresenta imagens distintas da morte: o destino nas sombras em que só há esquecimento e perda, e a imortalidade que aguarda os virtuosos - a divinização ou a imortalidade, pelo canto, na memória. Morrer, portanto, não é algo temido, quando se morre nobremente como Cleópatra, ou se se alcança a divinização, como Augusto, mas esta também é reservada ao vate sacro, que constrói um monumentum aere perennius regalique situ pyramidum altius. A morte, nos três casos, é convertida em um bem eterno.

\section{Referências bibliográficas}

BARCHIESI, Alessandro. Carmina: Odes and Carmen Saecularis. In: HARRISON, Stephen (Ed.). The Cambridge Companion to Horace. Cambridge: Cambridge University Press, p. 144-161, 2007.

BELTRÃO, Claudia. Lucretii poemata. A linguagem da política no De Rerum Natura. Mirabilia: Revista Eletrônica de História Antiga e Medieval, n. 7, p. 9-21, 2007.

Fortuna, uirtus e a sujeição do feminino em Horácio. Phoînix. Rio de Janeiro, v. 14, n. 1, p. $130-146,2008$.

Necessitas, Fortuna e Virtus em Horácio. Alethéia, v. 2, s/p, ago./dez. 2009.

Guerra, Direito e Religião na Roma Tardo-republicana: o ius fetiale. In: FUNARI, Pedro et. al. (Orgs.). História Militar do Mundo Antigo: Guerras e Representações. v. 2. São Paulo:

31 Idem, Carm., 2.20.21-24: absint inani funere neniae luctusque turpes et querimoniae; conpesce clamorem ac sepulcri mitte supervacuos honores.

32 Idem, Carm., 2.20.2-3.

33 Idem, Carm., 3.30.15-16: et mihi Delphica lauro cinge volens, Melpomene, comam. Tradução de Pereira (1986). 
Annablume, p. 119-138, 2012.

Monimenta mortuorum: memória e religião em dois monumentos ciceronianos. In: OMENA, Luciane Munhoz e FUNARI, Pedro Paulo (Orgs.) Práticas Funerárias no Mediterrâneo Romano. Jundiaí: Paco Editorial, p. 47-68, 2016.

BUSTAMANTE, Regina Maria da Cunha. Lemuria: apaziguando os mortos malfazejos na Roma antiga. Phoînix. Rio de Janeiro, v. 20, n. 2, p. 109-128, jul. 2014.

CURTIUS, Ernst. Literatura Europeia e Idade Média Latina. Brasília: Instituto Nacional do Livro, 1979. $760 p$.

ERNOUT, Alfred \& MEILLET, Antoine. Dictionnaire étymologique de la langue latine. Histoire des mots. Paris: Klincksieck, 2001. 833p.

FEENEY, Denis. Interpreting Sacrificial Ritual in Roman Poetry: Disciplines and their Models. In: BARCHIESI, Alessandro; RÜPKE, Jörg \& STEPHENS, Susan (Eds.). Rituals in Ink. A Conference on Religion and Literary Production in Ancient Rome. Stuttgart: Franz Steiner Verlag, p. 1-21, 2004.

FELDHERR, Andrew. "Dionysiac Poetics" and the Memory of Civil War in Horace 's Cleopatra Ode. In: BREED, Brian et al (Eds.) Citizens of Discord: Rome and its Civil Wars. Oxford: Oxford University Press, p. 223-232, 2010.

GRIFFIN, Jasper. Gods and Religion. In: HARRISON, Stephen (Ed.). The Cambridge Companion to Horace. Cambridge: Cambridge University Press, p. 181-194, 2007.

HABINEK, Thomas. The World of Roman Song. From Ritualized Speech to Social Order. Baltimore, London: The Johns Hopkins University Press, 2005. 344p.

HORSTER, Marietta. Living Religion: Professionals and Personnel. In: RÜPKE, Jörg (Ed.). A Companion to Roman Religion. Oxford: The Blackwell Publ., p. 331-341, 2007.

LORAUX, Nicole. Maneiras trágicas de matar uma mulher. Rio de Janeiro: Jorge Zahar Ed., 1988.

LOWRIE, M. Horace's Narrative Odes. Oxford: Clarendon Press, 1997. 140p.

MOREIRA, Daniel da Silva. Horácio, Odes, I.37. Apresentação e tradução. Nuntius Antiquus. Belo Horizonte, v. 11, n. 2, p. 143-152, 2015.

MOURÃO-FERREIRA, David. Vozes da Poesia Européia I: De Homero a Ibn Al-Sabuni. Colóquio/ Letras. Lisboa, n. 163, jan./abr. 2003. 246p.

NORTH, John. Roman Funeral Rituals and the Significance of the Naenia. Religion in the Roman Empire. Tübingen, v. 1, n. 1, p. 114-133, mar. 2015.

PEREIRA, Maria Helena Monteiro da Rocha. Romana. Antologia da Cultura Latina. Organização e tradução do latim. 2ª ed. Coimbra: Instituto de Estudos Clássicos, 1986. 292p.

PUTNAM, Michael. Artifices of eternity, Horace's four books of Odes. Ithaca: Cornell University Press, 1986. 352p. 
RICHLIN, Amy. Emotional Work: Lamenting the Dead. In: TYLAWSKY, Elizabeth \& WEISS, Charles. Essays in Honour of Gordon Williams. New Haven: Yale University Press, p. 229-248, 2001.

ROLLER, Duane. The World of Juba II and Kleopatra Selene: Royal Scholarship on Rome's African Frontier. New York: Routledge Classical Monographs, 2004. 352p.

SANTANGELO, Federico. The fetials and their ius. Bulletin of the Institute of Classical Studies. Londres, v. 51, p. 63-93, dez. 2008.

SCHEID, John. Libitina, Lubentina, Venus Libitina et les morts. In: PANCIERA, Silvio (Ed.). Libitina e dintorni. Libitina e i luci sepolcrali. Le leges libitinariae campane. lura sepulcrorum: vecchie e nuove iscrizioni. Roma: Quasar, p. 13-19, 2004.

WILLIAMS, Gordon. Horace Odes 1.12 and the succession to Augustus. Hermathena. Dublin, n. 117, p. 147-155, 1974.

Recebido em: 1 de novembro de 2017.

Aprovado em: 19 de novembro de 2017. 